\title{
Address databases for national SDI: Comparing the novel data grid approach to data harvesting and federated databases
}

\author{
SERENA COETZEE and JUDITH BISHOP \\ Department of Computer Science, University of Pretoria, Pretoria, 0002, South Africa \\ \{scoetzee,jbishop\}@ cs.up.ac.za
}

\begin{abstract}
The original purpose of addresses was to enable the correct and unambiguous delivery of postal mail. The advent of computers and more specifically geographic information systems (GIS) opened up a whole new range of possibilities for the use of addresses, such as routing and vehicle navigation, spatial demographic analysis, geo-marketing, and service placement and delivery. Such functionality requires a database which can store and access spatial data effectively. In this paper we present address databases and justify the need for national address databases. We describe models used for national address databases, and present our evaluation framework for an address database at a national level within the context of a spatial data infrastructure (SDI). The models of data harvesting, federated databases and data grids are analyzed and evaluated according to our novel framework, and we show that the data grid model has some unique features that make it attractive for a national address database in an environment where centralized control and/or coordination is difficult or undesirable.
\end{abstract}

Keywords: address data; national address database; SDI; data grid; information federation

\section{Introduction}

A hundred years ago addresses were used mostly for postal delivery and land administration: national postal services used them for letter and parcel delivery and the deeds registry needed them to correctly and unambiguously record property ownership. The advent of computers, and more specifically geographic information systems (GIS), opened up a whole new range of possibilities for the use of addresses, such as routing and vehicle navigation, spatial demographic analysis, geo-marketing, service placement and delivery, and electronic address verification, to name a few. The efficient and effective use of addresses in this way relies on the presence of a database that handles addresses in a spatial, rather than just a textual context.

In many countries address data producers operate on a local (town, county, local authority) level and their data has to be combined in various ways in order to provide access to an integrated national address database. In South Africa, for example, to gain access to integrated national address data one has to buy the dataset or subsets thereof from a limited number of private vendors. The cost of this data does not always justify buying it, and therefore one of the goals of our research to date is to investigate ways of providing address-related services rather than the address data itself. Our research also explores ways of providing integrated access to the various distributed address datasets thereby enabling independent service providers to provide address-related services with national and even international coverage. Integrating information from a number of heterogeneous databases into a single conceptual database is commonly referred to as information federation (Sheth and Larson, 1990). We have developed a novel evaluation framework, which we use to evaluate three information federation models that could be applicable. Although our evaluation is set in the South African context, the work has global relevance. The following three sections discuss spatial data infrastructures (SDIs), national address databases (NAD) and data grids and how we combine them in this paper. We conclude the introduction with an outline of our paper. 


\subsection{Spatial Data Infrastructure (SDI)}

Spatial Data Infrastructure (SDI) refers to the technologies, standards, arrangements and policies that are required to collate spatial data from various local databases, and to make these collated databases accessible and usable to as wide an audience as possible (Jacoby et al. 2002). National spatial data infrastructures emerged in the early 1980s in countries such as the USA and Australia. These first generation SDIs mostly followed a product-based approach. The next generation of SDIs are moving towards a more process-based approach focussing on the creation of a suitable infrastructure to facilitate the management of information access, instead of the linkage to existing and future databases (Crompvoets et al. 2005). Web services are a prominent and important feature of these process-based SDIs. Masser et al. (2007) further point out that the concept of an SDI is evolving from being a mechanism of data sharing to becoming an enabling platform that provides access to a wider scope of data and services, of a size and complexity that are beyond the capacity of individual organizations. SDI as an enabling platform can be viewed as an infrastructure linking people to data on the basis of the common goal of data sharing.

\subsection{National Address Database (NAD)}

A national address database (NAD) falls into the realm of a country's spatial data infrastructure. In the preparatory work of the European program for an SDI, INSPIRE (INfrastructure for SPatial InformationN in Europe), the concept of 'reference data' has been defined as a category of datasets, that plays a special role in the infrastructure. According to the INSPIRE definition (Rase et al., 2002), reference data must fulfil the following three functional requirements:

- Provide an unambiguous location for a user's information;

- Enable the merging of data from various sources; and

- Provide a context to allow others to better understand the information that is being presented.

Addresses fulfil all three requirements and have therefore been included explicitly in the final INSPIRE Directive in 'Annex 1', which contains the priority spatial reference datasets. This importance of address data as address reference data is applicable in other countries as well.

Due to their service, infrastructure and land administration responsibilities, it is commonly found that a local authority establishes and maintains address reference data for its area of jurisdiction (Coetzee et al., 2008). However, the need for address reference data for areas that extend across these jurisdictional boundaries calls for the collation of address reference data on a national and/or international scale. Example implementations of national address databases in Australia and Ireland follow the data harvesting model where all local data is loaded into a single centralized database that is under the control of a single organization.

\subsection{Data grids}

Grid computing started in the late 1990s as a distributed infrastructure for specific Grand Challenge applications executing on high-performance hardware. Since those initial days, it has evolved into a seamless and dynamic virtual environment (Baker et al. 2005). Although the initial focus of grid computing was on computational performance, it has expanded to address the needs of virtual organizations providing flexible, secure, coordinated resource sharing among collections of individuals, institutions and resources (Foster et al. 2001). There are different categories of grids such as computational grids, access grids and data grids, the last being the focus of this study. Data grids primarily deal with providing services and infrastructure for distributed data-intensive applications. Venugopal et al. (2006) identified a few unique features of data grids such as geographically distributed and heterogeneous resources under different administrative domains, and a large number of users sharing these resources and wanting to collaborate with each other. These features are similar to the challenges facing the development of a national SDI as mentioned in numerous SDI research papers (Georgiadou et al. 2005, McDougall et al. 2005, Tuladhar et al. 2005, Williamson et al. 2005, Rajabifard et al. 2006). They also 
correspond to the 'federation-by-accord' data sharing model mentioned by Harvey and Tulloch (2006). Thus there is a pre-existing link between the background to SDI and data grids which we explore in this paper.

\subsection{Combining SDIs, NAD and data grids}

The importance of address data as reference data together with the fact that address data is usually maintained on a local level but required on a larger scale implies that the principles of SDIs apply to the collation of address data into a NAD. The emerging concept of an SDI as the enabling platform that provides access to a wider scope of data and services, of a size and complexity that are beyond the capacity of individual organizations is closely related to the concept of a grid as the enabling platform for providing flexible, secure, coordinated resource sharing among collections of individuals, institutions and resources. Harvey and Tulloch (2006) describe some disadvantages to giving a single organization the authority over data production and sharing and report that a federation-by-accord, although difficult to establish, once integrated into ongoing activities, can become sustainable and a suitable vehicle for enhancing data sharing. Our novel approach to a national address database as a data grid corresponds to the 'federation-by-accord' data sharing model which can afford to lose a major player without ruining the entire model.

In this paper we explore three information federation models that could potentially support this 'federation-by-accord' data sharing model: data harvesting, federated databases and data grids. The large number of organizations involved in a national address database, as well as the lack of a single organization tasked with the management of a national address database, presents the data grid as an attractive alternative to the other two models. The data grid provides for a more loosely coupled architecture, thereby allowing for more diversity and heterogeneity. Both the data harvesting model and the federated database model require a single organization to take control. Our novel approach to a national address database as a data grid corresponds to the 'federation-by-accord' data sharing model which can afford to lose a major player without ruining the entire model.

\subsection{Outline of the paper}

The paper is divided into four sections. In section two we present the status of address data and justify the need for address databases at a national level. Section 3 describes our novel evaluation framework that is used to evaluate three information federation models. In section four we discuss three models for federation of information: data harvesting, a federated database, and a data grid. We analyse the models by comparing their purpose, how the unified view of the integrated data is established, how data updates are done, and whether transactions and service-orientation are supported.

In section five we evaluate and analyse the three models according to our novel evaluation framework and describe some implementation issues. The analysis of the three models shows that where a large number of organizations are involved, such as for a national address database, and where there is a lack of a single organization tasked with the management of a national address database, the data grid is an attractive alternative to the other two models. The data grid provides for a more loosely coupled architecture, thereby allowing for more diversity and heterogeneity. We explore this novel data grid approach to a national address database and also point out how this supports other decentralized approaches such as the 'federation-by-accord' data sharing model.

In summary, the objectives and contributions of this paper are to 1) sketch the status of spatial address data within the context of a SDI in a country like South Africa; 2) present our novel evaluation framework for national address databases; 3 ) describe potential information federation models for national address databases; and 4) evaluate these models according to our evaluation framework. 


\section{Spatial address data}

\subsection{Address data}

We define an address as a code or description for the fixed location of a home, building or other entity, and a spatial address as an address together with a coordinate for the geo-referenced location of the address. Our definition of an address does not include any information about the person or business residing at the address. Table 1 below lists sample addresses from a number of countries.

Table 1. Sample Addresses

\begin{tabular}{llll}
\hline \multicolumn{1}{c}{ Country } & \multicolumn{1}{c}{ Address } & \multicolumn{1}{c}{ Country } & \multicolumn{1}{c}{ Address } \\
\hline Germany & Waldparkstrasse 67c & Spain & Calle Agazado, 23 \\
& DE-22605 Hamburg & & Molino de la Hoz \\
& GERMANY & & Las Rosas \\
& & & ES-28230 MADRID \\
& & & SPAIN \\
\hline Japan & 14F Sphere Tower Tennoze & Turkey & 27 Gül Sokak \\
& 2-2-8 Higashishinagawa & & 61250 Yomra \\
& Shinagawaku & & Trabzon \\
& Tokyo 140 0002 & Turkey \\
& Japan & & \\
\hline \multirow{2}{*}{ New Zealand } & 6 Upland Road & United Kingdom & Russell House \\
& Kelburn & & 4395 Station Road \\
& Wellington 6005 & & Porchester \\
& New Zealand & FAREHAM \\
& & PO16 8BQ \\
\hline
\end{tabular}

A spatial reference system is used to identify locations on the surface of the Earth and addresses in an addressing system can be described as locations in a spatial reference system (Coetzee et al. (2008). There are three types of reference systems:

1. a coordinate reference system specifies the location by reference to a datum;

2. a linear reference system specifies the location by reference to a segment of a linear geographic feature and distance along that segment from a given point; and

3. a geographic identifier reference system specifies the location by a label or code.

As per ISO 19112, - Geographic information - Spatial referencing by geographic identifiers, a geographic identifier reference system comprises a related set of one or more location types, that may be related to each other through aggregation or dis-aggregation, possibly forming a hierarchy. Clodoveu and Fonseca (2007) conclude that this notion of an address as a hierarchy is commonly found in addressing systems around the world. An example of a geographic identifier reference system in South Africa would be Country > Province > Municipality > Suburb; and a location instance in this system would be South Africa > Gauteng > City of Tshwane Metropolitan Municipality > Hatfield. The similarity between a geographic identifier reference system and an addressing system can be illustrated by extending the geographic identifier reference system to include street names and street numbers, as in Country > Province > Municipality > Suburb > Street > Street Number. This allows a street address to be represented as a location instance of this reference system: South Africa > Gauteng > City of Tshwane Metropolitan Municipality > Hatfield > Pretorius Street > 1083. The British address standard, BS 7666, was developed in line with this notion of a geographic identifier reference system, proving that an addressing system can be viewed as a geographic identifier reference system. 
However, if address numbers are assigned according to distance, then thoroughfare addressing can be regarded as a type of linear referencing system, as opposed to a geographic identifier reference system. For example, if address numbers are increased at one per meter, then ' 310 King Street' means: 'Proceed 310 meters along King Street from its beginning, then look to the even-numbered side of the street.', i.e. route, reference point, distance, offset.

In the extreme case, addressing can even resemble a coordinate reference system. For example, in South Africa addresses in remote rural areas are captured as 'dots' either with GPS devices or from aerial photography. Each one of these dots represents an address. The geographic identifiers associated with the dot could include the province, municipality and village name, but no more than that. To locate the address, one has to know the coordinate. Over time these addresses could evolve into addresses as we more commonly know them, i.e. including street names and numbers.

Thus, one can consider addressing to fall into all three types of reference systems, or consider addressing to be a fourth type of reference system due to the potential many-to-many relationships between, for example, an address and what is being addressed such as a building or a land parcel.

The importance of address data as reference data is illustrated in the preparatory work of the European program for an SDI, INSPIRE (INfrastructure for SPatial InformationN in Europe), where the concept of 'reference data' has been defined as a category of datasets, that plays a special role in the infrastructure. According to the INSPIRE definition (Rase et al., 2002), reference data must fulfil the following three functional requirements:

- $\quad$ Provide an unambiguous location for a user's information;

- Enable the merging of data from various sources; and

- Provide a context to allow others to better understand the information that is being presented.

Addresses fulfil all three requirements: in numerous legacy and modern IT systems, address information is recorded with the purpose of having an unambiguous identification of the real property, customer, citizen, business or utility entity in question. Secondly, addresses are used as one of the most important mechanisms to merge or link information from different sources together, e.g. when a bank uses the customer's address to look up information on real property or insurance. Last but not least, addresses are used every day by citizens, businesses and government as a human understandable description of the location of a specific piece of information; for example, the address label on letters or goods for delivery is meant to give every actor in the delivery process a clear understanding of the desired final destination. As a result of these considerations, addresses have been included explicitly in the final INSPIRE Directive in 'Annex 1', which contains the priority spatial reference datasets.

The typical responsibilities of local governments often cause them to become the custodians of street address and other land related data in a country (Williamson et al. 2005). The challenge that faces many countries is the establishment of national datasets from these numerous local datasets. There is often little or no cooperation between local and national government, and the trend to manage and maintain the national address database by adding local data to a single centralized database and periodically publishing the national database is seen in the examples of national databases described by Jacoby et al. (2002) and McDougall et al. (2005) for Australia, by Morad (2002) for the UK, and by Fahey and Finch (2006) for Ireland.

The term national address database or dictionary (NAD) is sometimes used to refer both to any address database that claims to have national coverage (regardless of the data provider), as well as to an officially regulated register of addresses. To avoid confusion, in this paper we refer to an official register of addresses as a national address register (NAR), and we use the term national address database (NAD) to include any national address database whether it is an officially regulated database or not.

\subsection{The need for address data}

Spatial address databases at all levels of government are required for ensuring services to a country's citizens. In South Africa, for example, according to the Bill of Rights in the constitution every citizen has 
the right to have access to, among others, adequate housing, a basic education, health care services, sufficient food \& water, and social security. The constitution further stipulates how the different levels of government should ensure that these rights are delivered. However, a critical part of being able to deliver, for example, running water to citizens, is knowing where the water has to be supplied. In the private sector there is also a need for a national spatial address database. As an example, South Africa's Financial Intelligence Centre Act (FICA) was written to assist in the identification of the proceeds of unlawful activities and the combating of money laundering. For that reason, customers of financial services institutions must provide proof of their residential address before opening an account. But how does a bank know that the address of a prospective customer is valid?

Other examples of address databases use are social services delivery where density of address data is used to prioritize the planning and roll-out of social services such as health clinics, schools and social service payout points in a country. Refer to Figure 1 for a map that shows the density of street addresses in Gauteng, a province of South Africa; goods delivery where courier, freight and logistics companies use spatial address databases to route their vehicles to a requested delivery address; credit application where the residential address of the applicant is verified against a spatial address database; household surveys where the spatial address database is used for the delimitation of enumeration areas, as well as the planning and execution of surveys; elections for the delimitation of voting districts and the identification of voting stations in a country; emergency services to locate the emergency, and to route the relief team to the site (Yildirim and Yomralioglu 2004).

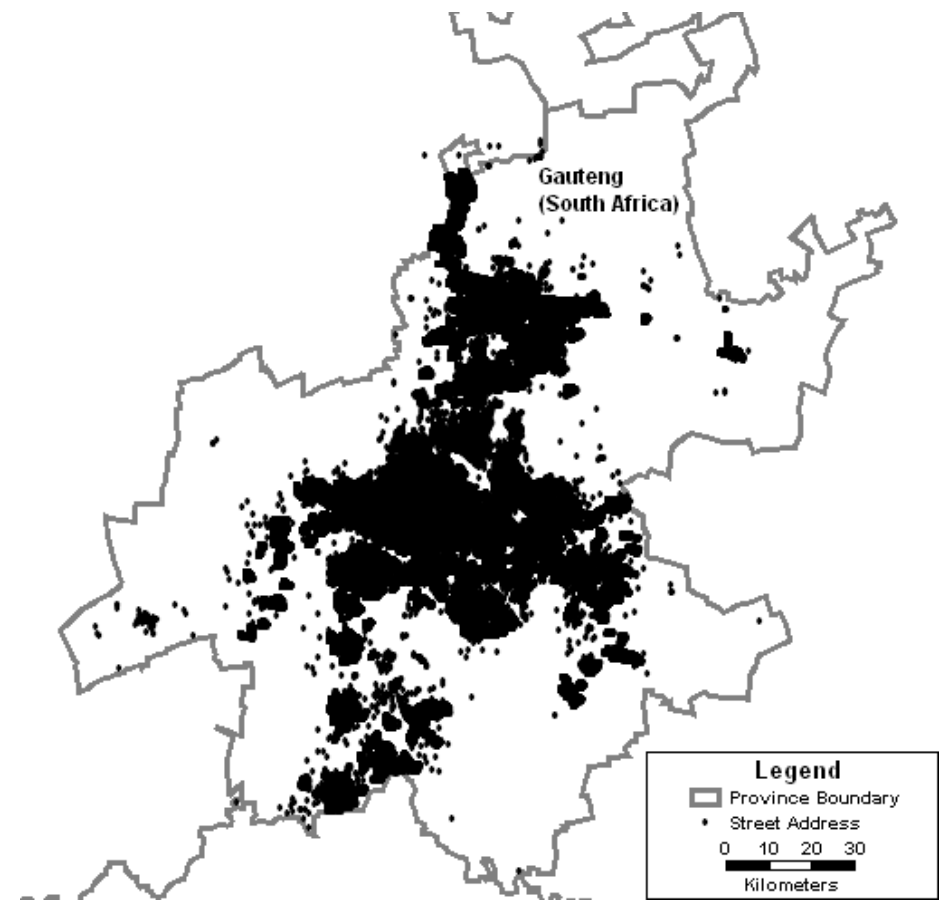

Figure 1. Street addresses in Gauteng (Source: AfriGIS NAD)

\subsection{Spatial address data in South Africa}

There is a large variety of address types in use in South Africa, as can be seen from the draft South African address standard (SANS1883), which caters for street addresses, building addresses, farm addresses, informal addresses, intersection addresses, landmark addresses, various forms of postal addresses and site addresses (Coetzee and Cooper, 2007). The address type most commonly in use, is the street address type for which we have listed the Backus Naur form (BNF) in Figure 2. The map in Figure 3 shows a typical street address in a suburb in South Africa. 


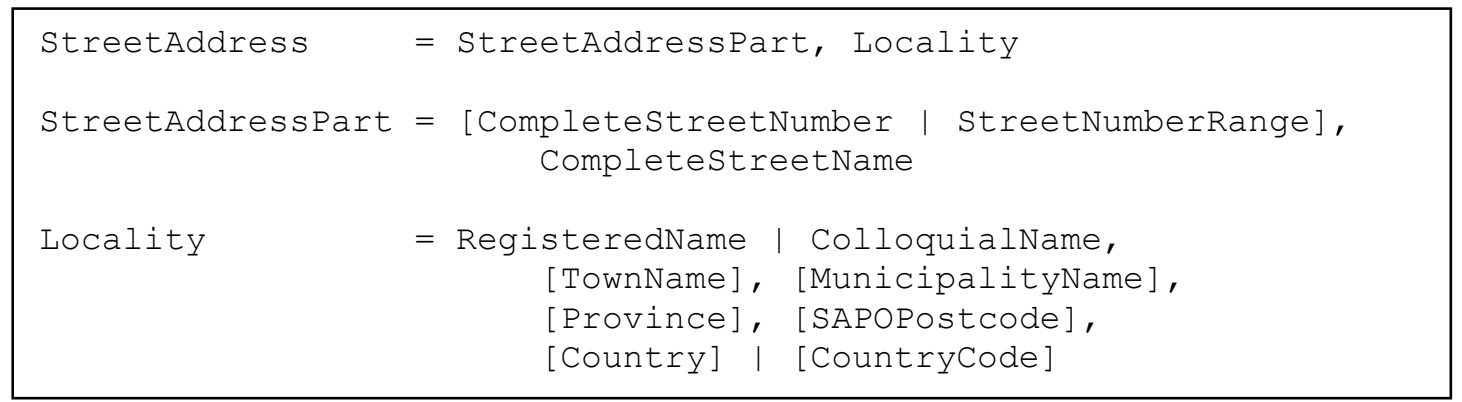

Figure 2. The elements of a South African street address (SABS, 2008).

In formal areas the StreetAddressPart is usually assigned by the municipality, but in informal areas and squatter camps this part of the address is randomly assigned. There is also the history of apartheid era townships in South Africa where only street names and no street numbers were assigned.

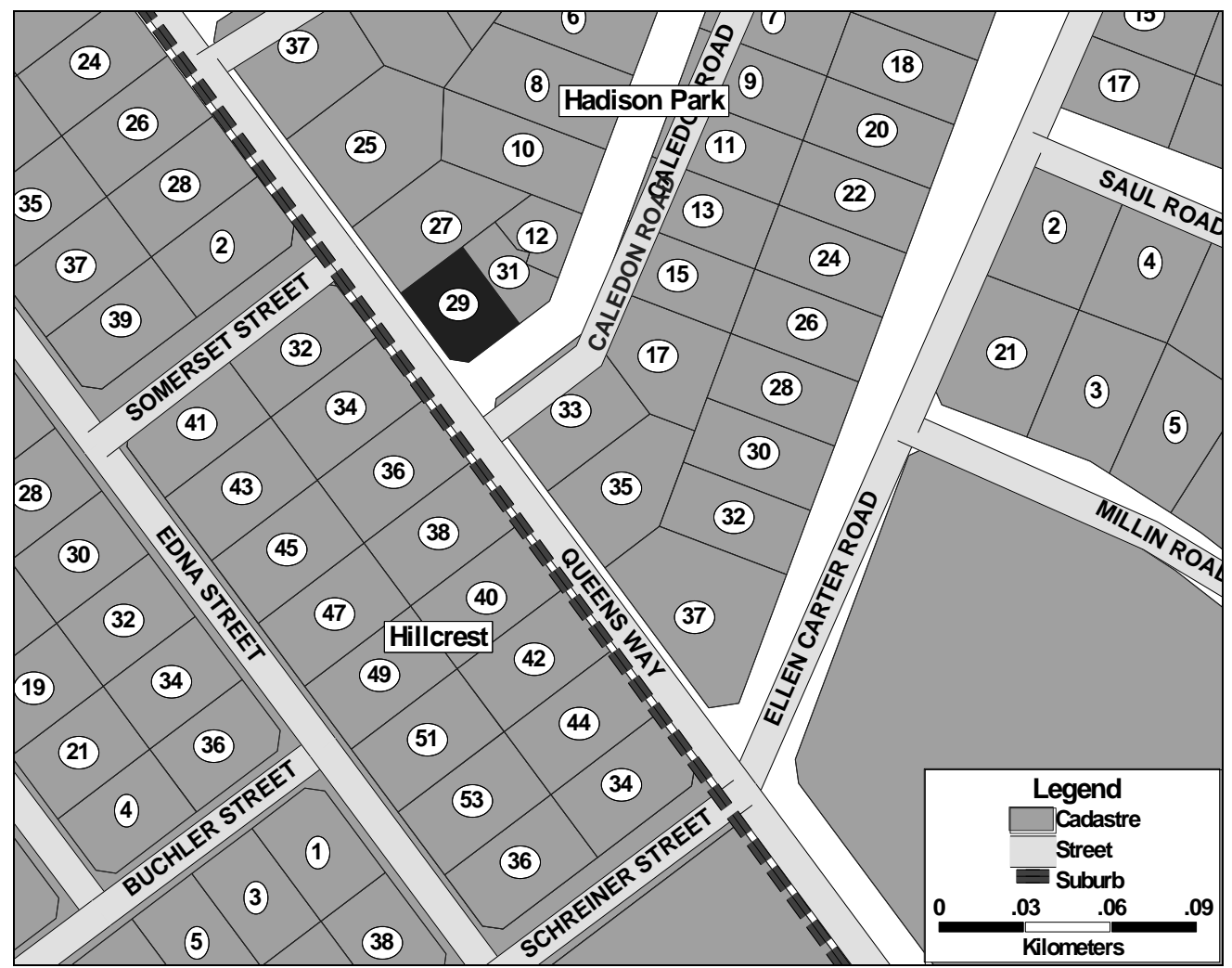

Figure 3. Hillcrest and Hadison Park in Kimberley (Source: AfriGIS NAD)

The Locality part of the address has one mandatory item: either the name of the suburb as registered at the surveyor general, or the name that is used colloquially for the area. The fact that people use both registered names and colloquial names results in ambiguity (and controversy) in names as used by the surveyor general, municipalities, the SA post office and the general public. For example, refer to 29 Queens Way in Figure 3. Because of the ambiguity in suburb names, an incoming address verification request for '29 Queens Way Hillcrest' could refer to any of the suburbs named 'Hillcrest' in Durban, Pretoria, Benoni, Kimberley, Wellington, Mthatha or Cape Town, of which only the suburb name 'Hillcrest' in Durban and Pretoria has been officially registered at the surveyor general. Further, since there is ambiguity in suburb boundaries '29 Queens Way' might actually be in Hadison Park, the suburb adjacent to the suburb named Hillcrest.

In 2001 South Africa was re-demarcated into 262 municipalities, and since then South Africa has been governed according to these municipal boundaries. However, people still use the 'town' names referring to the pre-2001 town councils in addresses. For example, the Akasia, Centurion and Pretoria town councils together with some other pre-2001 rural councils have been integrated to form the City of Tshwane metropolitan municipality. The names and boundaries of provinces and municipalities are 
determined and legalized by the Municipal Demarcation Board. Thus there is no ambiguity for the MunicipalityName and Province.

There are various sources of address data in South Africa, and some of these are listed in Table 2. The list is not comprehensive, but it illustrates that while there is not a single national address database in South Africa, there are a number of producers of address data that can each contribute to a national database of addresses.

The South African Spatial Data Infrastructure Act of 2003 was finally enacted in 2006, and the appointment of the Committee for Spatial Information (CSI) is currently (still) in progress. The act states that the CSI will appoint data custodians for SDI datasets. Thus, at the moment there is not a government appointed custodian for address data, and all the issues relating to custodianship are still open and have to be debated before any decision on custodianship is taken. It is therefore expected that custodianship will not be decided soon.

Table 2. Address data producers in South Africa

\begin{tabular}{|c|c|c|c|c|}
\hline Source & Type of data & Purpose & $\begin{array}{l}\text { Typical } \\
\text { Coverage }\end{array}$ & Formats \\
\hline $\begin{array}{l}\text { GIS departments at } \\
\text { municipalities }\end{array}$ & $\begin{array}{l}\text { Land parcels and their assigned } \\
\text { street names and numbers }\end{array}$ & $\begin{array}{l}\text { Support function to other } \\
\text { municipal departments }\end{array}$ & Municipality & $\begin{array}{l}\text { Paper maps, CAD } \\
\text { drawings, or GIS } \\
\text { databases }\end{array}$ \\
\hline $\begin{array}{l}\text { Property valuation } \\
\text { rolls at } \\
\text { municipalities }\end{array}$ & $\begin{array}{l}\text { Property description (as per deeds } \\
\text { registry) together with a postal } \\
\text { address }\end{array}$ & Property Valuation & Municipality & Paper printouts \\
\hline $\begin{array}{l}\text { Consulting town } \\
\text { planners }\end{array}$ & $\begin{array}{l}\text { Plan showing the layout of } \\
\text { proposed erven and their assigned } \\
\text { street names and numbers for new } \\
\text { development }\end{array}$ & Town Planning & Town or suburb & $\begin{array}{l}\text { Paper maps, CAD } \\
\text { drawings, or GIS } \\
\text { databases }\end{array}$ \\
\hline $\begin{array}{l}\text { South African Post } \\
\text { Office }\end{array}$ & $\begin{array}{l}\text { A list of SA post office approved } \\
\text { place names with their postcodes, } \\
\text { no spatial information included }\end{array}$ & Postal mail delivery & National & $\begin{array}{l}\text { Comma delimited } \\
\text { text file }\end{array}$ \\
\hline $\begin{array}{l}\text { Statistics South } \\
\text { Africa }\end{array}$ & $\begin{array}{l}\text { Database of dwelling locations, } \\
\text { address not always included }\end{array}$ & Household surveys & $\begin{array}{l}\text { Per area as } \\
\text { required for a } \\
\text { survey }\end{array}$ & $\begin{array}{l}\text { Proprietary GIS } \\
\text { databases }\end{array}$ \\
\hline $\begin{array}{l}\text { State IT Agency } \\
\text { (SITA) }\end{array}$ & $\begin{array}{l}\text { Address data sourced from a } \\
\text { single private company }\end{array}$ & $\begin{array}{l}\text { Provide data and services } \\
\text { to government } \\
\text { departments only }\end{array}$ & National & $\begin{array}{l}\text { Proprietary GIS } \\
\text { databases }\end{array}$ \\
\hline $\begin{array}{l}\text { Private Companies } \\
\text { (non-spatial) }\end{array}$ & $\begin{array}{l}\text { Compiled from the customer } \\
\text { databases of various } \\
\text { organizations, often includes the } \\
\text { name of an individual or business }\end{array}$ & Direct marketing & $\begin{array}{l}\text { Provincial, } \\
\text { National }\end{array}$ & $\begin{array}{l}\text { Relational database } \\
\text { tables or comma } \\
\text { delimited text files }\end{array}$ \\
\hline $\begin{array}{l}\text { Private Initiatives } \\
\text { (spatial) }\end{array}$ & $\begin{array}{l}\text { Source address data from data } \\
\text { producers listed above, and } \\
\text { aggregate it into a national } \\
\text { database }\end{array}$ & $\begin{array}{l}\text { Address-related service } \\
\text { provision, either by the } \\
\text { company itself or sold to a } \\
\text { third party }\end{array}$ & National & $\begin{array}{l}\text { GIS database } \\
\text { formats }\end{array}$ \\
\hline
\end{tabular}

Due to the current lack of a single government initiative to create a definitive national address database or register for public use, private organizations have identified and leveraged the business benefit of providing address-related products and services. These organizations source the address data for their national address databases from the sources listed in Table 2 and collate the data into a national address database. The privately owned national address databases are distributed on a quarterly basis to clients in a single file in various formats. Clients of the national address databases include the private sector such as debt collectors, media companies, and financial institutions (banks and insurance companies) as well as 
the public sector such as SITA, Statistics South Africa, provincial and national departments of housing, and provincial and national transport authorities.

The cost of maintaining a national address database is high, and there are only a few organizations such as the major banks and large government organizations who can afford to buy the complete national address database. Private organizations have therefore started looking at new sources to recover some of the cost of data maintenance, and have started providing address-related services for which a user pays a small once-off fee for the service and use of data. For example, instead of paying hundreds of thousands of Rands for the national address database and then still having to implement an address verification service, the user pays R1 (approximately US\$0.12 at the current exchange rate) or less (depending on volumes) to have a single address verified. Such a service makes the address data available to a much wider audience.

Regardless of how a national address data will be compiled for South Africa in the future - whether there will be one (or more) custodian(s) for address data, or whether a national initiative for a single national address database emerges, or whether address data will still be provided by private organizations - these address-related services are essential to making address data available to as wide an audience as possible. Based on this current scenario of address data in South Africa, we developed the evaluation framework that is described in the following section.

\section{Evaluation framework}

In this section we describe the framework that we use to evaluate potential information federation models for a national address database (NAD) in the South African context. Our paper provides a technical evaluation of the models for a national address database, regardless of whether the national address database is officially regulated or not. To facilitate the evaluation, we present an architecture of conceptual layers for our national address database. Figure 4 illustrates these layers. In this section we describe the purpose of each layer, and then list the criteria of our framework by reference to the layered architecture.

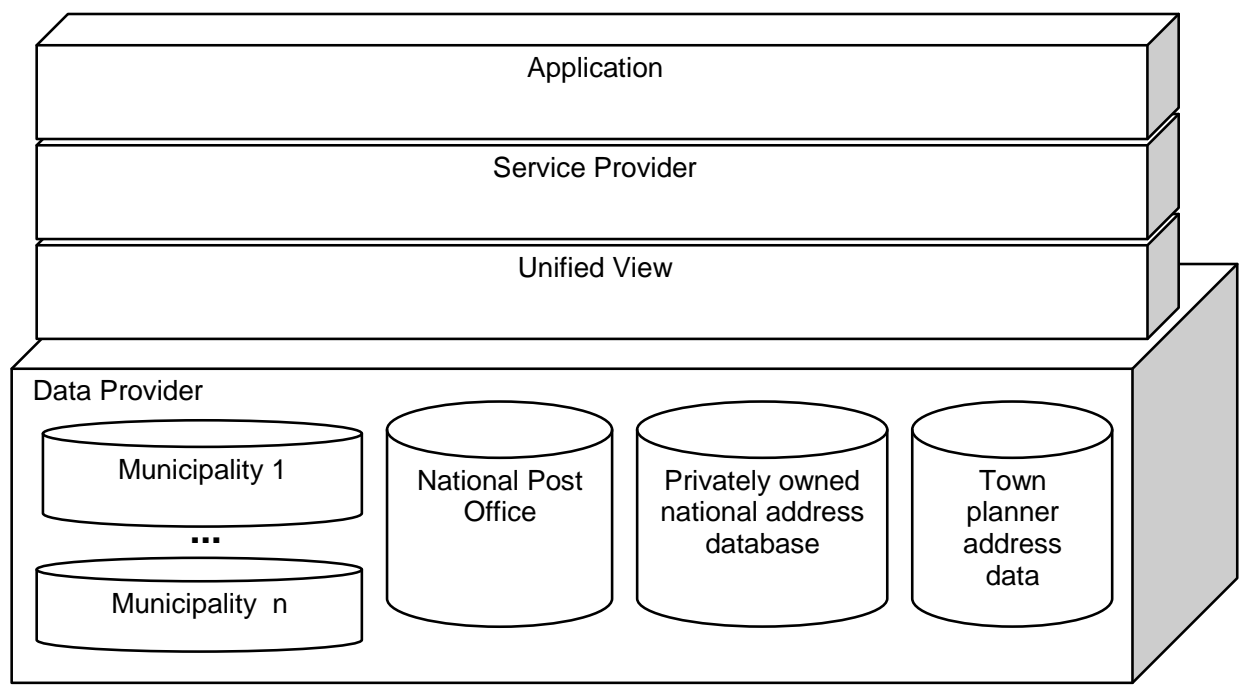

Figure 4. National address database

The criteria of the framework are based on the requirements for the establishment, maintenance and use of a national address database. The data provider layer contains the databases from the various address data providers. The unified view layer provides one or more common interfaces to any third party wanting to access the national address database. It also provides a unified view of the national address database, thus creating the illusion of working with a single database. In the service provider layer vendors provide services against the national address database. Examples of services are an address verification service, an address geocoding service, or a mapping service. The application layer represents any application that 
makes use of a vendor service, for example, a home loan application form at a bank that makes use of an address verification service.

The first three criteria in our evaluation framework address heterogeneity in infrastructure, data providers and naming conventions. The following three criteria, namely address dynamics, accessibility and security, focus on issues around making the address data available to as wide an audience as possible. The final criterion addresses organizational issues of coordinating a national address database.

Table 3. Infrastructure

Criteria Description

Operating System Data and service providers should be free to use the operating system of choice.

Database A data provider should be free to store the address data in a DBMS (Oracle, SQL Server, ArcSDE, ESRI

Management SHP files, MapInf files, etc.) of choice.

System (DBMS)

Address Format Although address-related services should be based on a standardized address format, the unified view layer should accommodate the differences in address representation of the individual data providers.

Table 4. Data providers

\begin{tabular}{ll}
\hline \multicolumn{1}{c}{ Sub-Criteria } & \multicolumn{1}{c}{ Description } \\
\hline Coverage area & $\begin{array}{l}\text { Variation in the size and location of the coverage of address databases supplied by data providers should } \\
\text { be allowed, and data access should be optimized for this, i.e. don't search for a Cape Town address in } \\
\text { the Johannesburg database. }\end{array}$ \\
\hline $\begin{array}{l}\text { Decentralized } \\
\text { source of data }\end{array}$ & The reality of many decentralized sources of address data providers must be catered for. \\
\hline $\begin{array}{l}\text { Multiple data } \\
\text { providers per area }\end{array}$ & $\begin{array}{l}\text { A data request should consider addresses from all the data providers, and resolve duplicates, ambiguities } \\
\text { and potential semantic differences. }\end{array}$ \\
\hline
\end{tabular}

Table 5. Naming

\begin{tabular}{cl}
\hline Sub-Criteria & \multicolumn{1}{c}{ Description } \\
\hline Suburb Names & $\begin{array}{l}\text { Enough information (such as alias tables) as well as disambiguating functionality should be provided to } \\
\text { resolve between new official and colloquial names for suburbs. }\end{array}$ \\
\hline Name Changes & $\begin{array}{l}\text { Enough information (such as alias tables) as well as disambiguating functionality should be provided to } \\
\text { resolve between new and old names of suburbs and streets. }\end{array}$ \\
\hline
\end{tabular}

Table 6. Address Dynamics

\begin{tabular}{ll}
\hline \multicolumn{1}{c}{ Sub-Criteria } & \multicolumn{1}{c}{ Description } \\
\hline $\begin{array}{l}\text { New } \\
\text { developments }\end{array}$ & $\begin{array}{l}\text { Address data for newly developed areas should become available as soon as possible. A quarterly update } \\
\text { cycle is too long. }\end{array}$ \\
\hline $\begin{array}{l}\text { Previously un- } \\
\text { addressed }\end{array}$ & $\begin{array}{l}\text { Newly assigned addresses in previously unaddressed areas should be accessible as soon as possible in } \\
\text { order to speed up service delivery to the areas as part of the development initiative in a country. }\end{array}$ \\
\hline $\begin{array}{l}\text { Address cross } \\
\text { checking }\end{array}$ & $\begin{array}{l}\text { Data providers should be able to cross check the availability of address data in areas for which they plan } \\
\text { to produce address data. }\end{array}$ \\
\hline $\begin{array}{l}\text { Feedback from } \\
\text { users to data } \\
\text { providers }\end{array}$ & $\begin{array}{l}\text { Users of the address data should be able to provide feedback to data providers about the correctness and } \\
\text { accuracy of address data. }\end{array}$ \\
\hline
\end{tabular}


Table 7. Accessibility

\begin{tabular}{ll}
\hline \multicolumn{1}{c}{ Sub-Criteria } & \multicolumn{1}{c}{ Description } \\
\hline $\begin{array}{l}\text { Providing services } \\
\text { (service providers) }\end{array}$ & $\begin{array}{l}\text { Service providers should be able to provide value-adding address-related services on top of the unified } \\
\text { view of the national address data. These services should be provided in a standard and well-known } \\
\text { framework such as web services, and more specifically web feature services as specified by the Open } \\
\text { Geospatial Consortium (OGC). }\end{array}$ \\
\hline $\begin{array}{l}\text { Billing and } \\
\text { Accounting }\end{array}$ & $\begin{array}{l}\text { The information federation model should allow a two-level billing and accounting system for both data } \\
\text { use, and the use of vendor-supplied services. }\end{array}$ \\
\hline $\begin{array}{l}\text { Using services } \\
\text { application } \\
\text { developers) }\end{array}$ & $\begin{array}{l}\text { Application developers should be able to seamlessly integrate into their applications both services that } \\
\text { provide access to the unified view of the national address database as well as the vendor-supplied } \\
\text { services. }\end{array}$ \\
\hline $\begin{array}{l}\text { Access anytime } \\
\text { Access through these services to the national address database should be instantaneous and available all } \\
\text { the time. }\end{array}$ \\
$\begin{array}{l}\text { Access from } \\
\text { anywhere }\end{array}$ & $\begin{array}{l}\text { Access to the national address database should be available from as many platforms as possible } \\
\text { including client desktops, personal digital assistants (PDA) and/or mobile phones. }\end{array}$ \\
\hline $\begin{array}{l}\text { Ease of publishing } \\
\text { data (providing } \\
\text { data) }\end{array}$ & \begin{tabular}{l} 
Facilities for publishing address data should be easy and should not require specialized IT support. \\
\hline
\end{tabular}
\end{tabular}

Table 8. Security

\begin{tabular}{ll}
\hline \multicolumn{1}{c}{ Sub-Criteria } & \multicolumn{1}{c}{ Description } \\
\hline $\begin{array}{l}\text { User } \\
\text { Authentication }\end{array}$ & Access to the national address database should be restricted to authenticated users. \\
\hline Access & $\begin{array}{l}\text { Data providers should be able to specify how and to whom (which group of people) their data is } \\
\text { available. }\end{array}$ \\
\hline Privacy & The data in the national address database should be protected against unauthorized access. \\
\hline
\end{tabular}

Table 9. Organizational Issues

\begin{tabular}{ll}
\hline \multicolumn{1}{c}{ Sub-Criteria } & \multicolumn{1}{c}{ Description } \\
\hline $\begin{array}{l}\text { Official } \\
\text { custodians and } \\
\begin{array}{l}\text { unofficial data } \\
\text { providers }\end{array}\end{array}$ & $\begin{array}{l}\text { The information federation model for a national address database should support the fact that there could } \\
\text { be both officially regulated address data providers, supporting an official national address register, and } \\
\text { unofficial address data providers, supporting national address databases in general. }\end{array}$ \\
\hline
\end{tabular}

\section{Information federation models for a national address database}

In this section we describe three distributed information federation models, namely data harvesting, federated databases and data grids. The models are commonly used for the federation of information but each has its own distinctive characteristics making it suitable for specific circumstances. We provide a description for each model, describe its purpose, and give examples of its implementation. In order to further analyse the models, we list the sequence of events for performing a search service in each of the models. We describe each model by dividing it into four layers: application, search service, unified view, and the distributed data themselves. These layers correspond to the application, service provider, unified view and data provider layers in our conceptual architecture of a national address database. The difference between the models mainly lies in the way the data is stored and how the unified view of the distributed databases is achieved and maintained. 


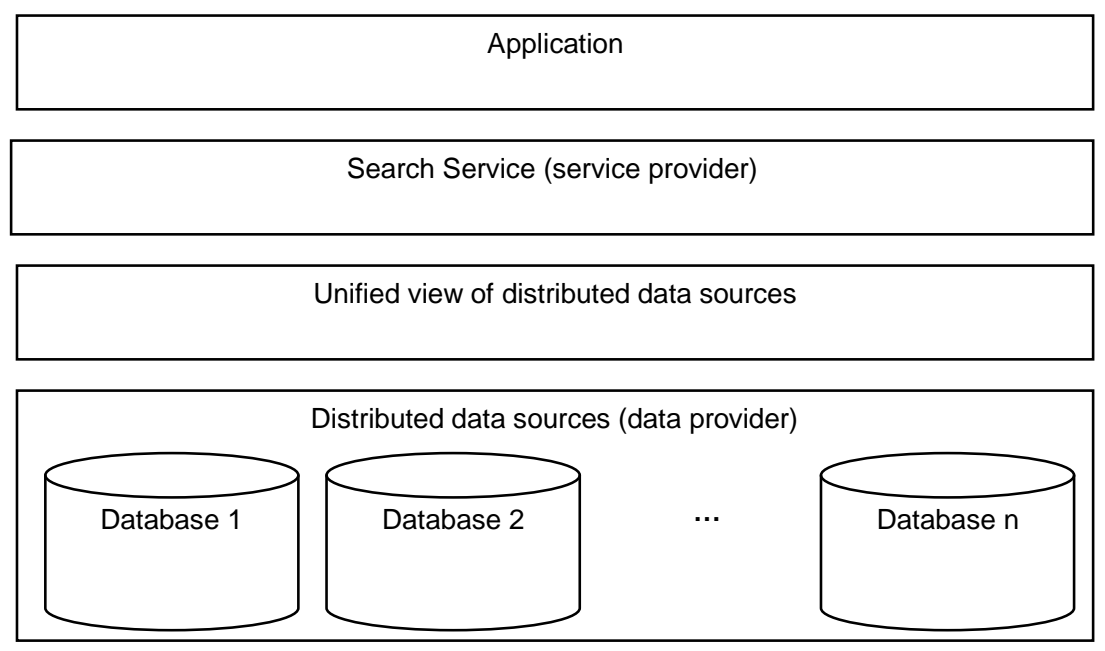

Figure 5. Information federation models

\subsection{Data harvesting}

In this model, data from a number of distributed databases is regularly harvested into a single centralized database, sometimes also referred to as data warehousing. Any search service accesses the single centralized database only, and does not have access to the distributed databases. The harvesting of data is either done online, e.g. through a web service, that pulls the data from one of the distributed databases and imports it into the centralized database; or harvesting is done offline by exporting the data from the distributed database and importing it into the centralized database. The underlying heterogeneity of the distributed databases, such as syntactic and semantic differences, is resolved when the data is harvested.

The centralized database is managed by a single organization, whereas the distributed databases are owned and managed independently. As long as one can export data into a format that can be imported into the centralized database, the management of the data in the distributed database is up to its owners.

The centralized database could be a relational database, but just as well a spatial or object-oriented database. The format (relational, spatial or object-oriented) of the individual distributed databases is also independent from the format of the centralized database. Data warehouse support provided by database management software such as Oracle, SQLServer or MySQL can be used to implement a centralized database.

Data queries are processed and optimized by the database management system (DBMS) that is used for the centralized database, but updates to individual data records are not possible as there is a uni-directional flow of data from the distributed databases into the centralized database. A centralized database has the potential of becoming a bottleneck but these can be resolved by load balancing techniques such as replication or mirroring of the centralized database. Since the centralized database is mostly read-only with regular and very specific types of updates, load balancing is easy to implement.

Figure 6 shows the sequence of events when performing a search for data in the data harvesting model. The dotted arrows indicate flow of harvested data.

1. The application calls the search service.

2. The search service queries the centralized database.

3. The resulting data is passed back to the search service.

4. The search service passes the resulting data back to the application. 


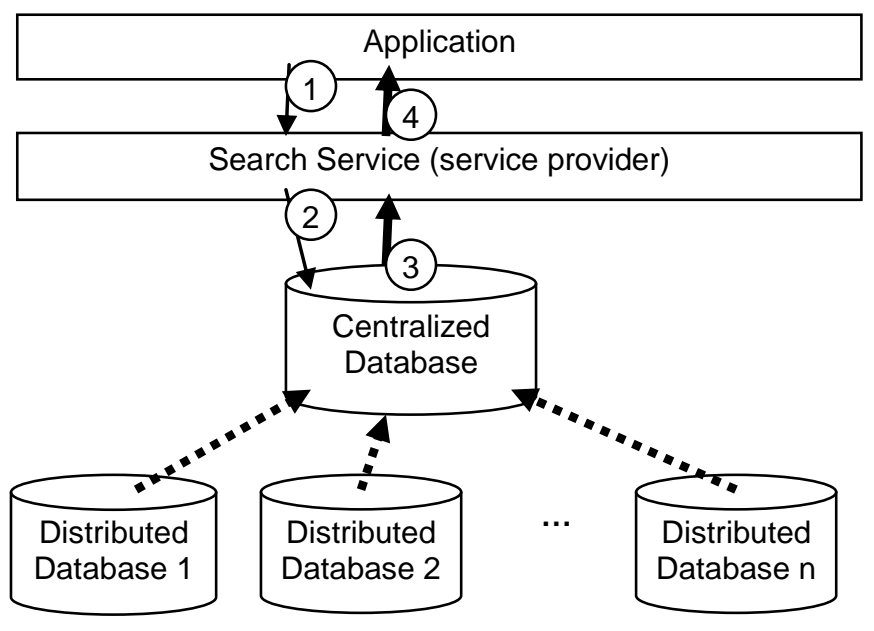

Figure 6. The data harvesting model

\subsection{Federated database}

A federated database (FDBS) is a collection of cooperating but autonomous component database systems (Sheth and Larson 1990). A significant aspect of a component database is the fact that it can continue with its local operations while at the same time participating in the federation. Federated databases are used to integrate existing diverse databases to provide a uniform, consistent interface for querying the underlying databases, and are sometimes also referred to as enterprise information integration. Federated databases accommodate any kind of underlying heterogeneity in terms of representation and syntax in the component databases. Federated databases are tightly integrated systems and usually maintained by a single organization.

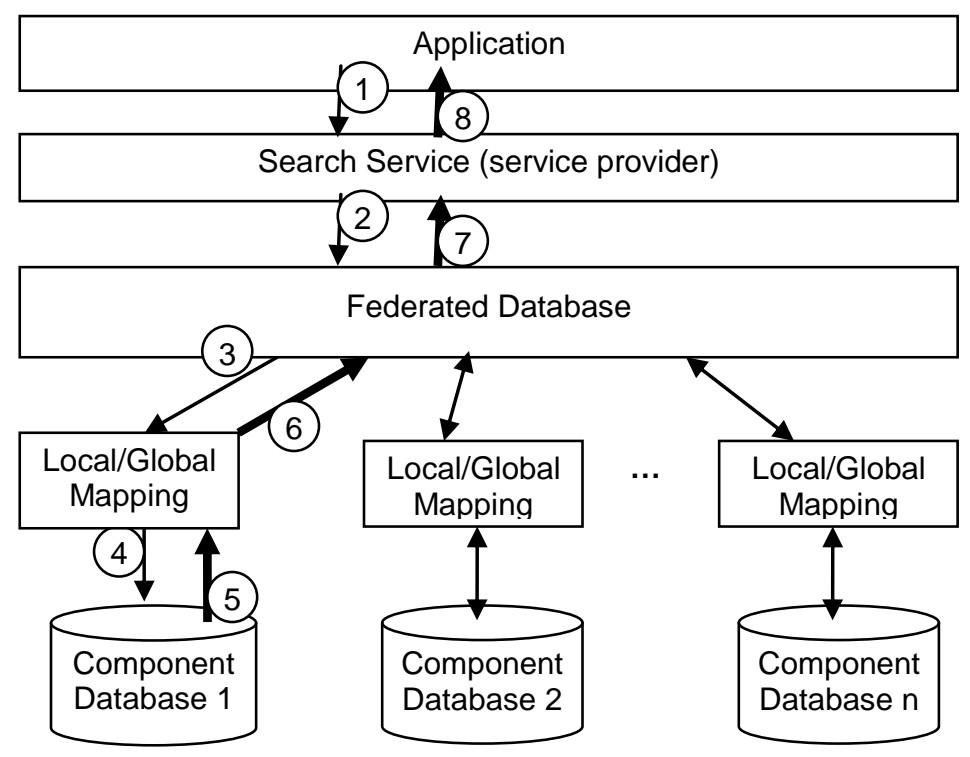

Figure 7. The federated database model

A database management interface provides access to the FDBS, and data records are both read and written frequently, thus necessitating transactions. Some form of query language, such as SQL for relational databases, is used to construct queries. The FDBS interprets, optimizes and executes the queries against the underlying component databases and provides results back to the querying process. The federation is established by mapping the local representation of a component database to the global representation of the federated database. The purpose of an FDBS is to integrate existing heterogeneous 
databases and to provide a uniform and consistent interface for querying and updating data in the underlying databases.

Figure 7 shows the sequence of events when performing a search for data in the federated database model. The thick arrows indicate data flow.

1. The application calls the search service.

2. The search service queries the federated database.

3. The query is translated into a form that the component database understands, i.e. there is a translation from global to local representation and syntax. Semantic differences, as well as data schema differences, in the underlying component databases are resolved.

4. The query arrives at the component database and is executed.

5. The resulting data is mapped from local to global representation and syntax. Semantic and data scheme differences are resolved.

6. The resulting data (global view) is passed back to the federated database.

7. The federated database passes the resulting data back to the search service.

8. The resulting data is passed back to the application.

The concept of a federated database has been applied to georeferenced data where existing spatial databases are integrated into a single map view with a uniform, consistent interface for querying, navigating and/or updating the underlying spatial databases. Tuladhar et al. (2005) propose a federated data model for distributed cadastral databases for land administration in Egypt. Another example would be a single map generated at a local authority that displays land parcel boundaries from an ArcSDE database in the town planning department and street centre line data from an Oracle spatial database in the engineering department. IBM's Information Integrator together with the IBM Websphere Federation Server (refer to www.ibm.com), give real-time access to distributed databases in such diverse formats as Oracle databases, Microsoft Excel spreadsheets and flat files. A consistent view of data is created and federated access to the multiple data sources is provided.

\subsection{Data grid}

The term 'grid' has been used in many ways, including everything from advanced networking to artificial intelligence. To eliminate confusion, in our discussion we stick to the definition of a grid as defined by the Open Grid Forum (Treadwell, 2006): 'A system that is concerned with the integration, virtualization, and management of services and resources in a distributed, heterogeneous environment that supports collections of users and resources (virtual organizations) across traditional administrative and organizational domains (real organizations).' We thus exclude cluster computing or so called computing on demand which is provided and marketed as 'grid' by some of the commercial companies, including Oracle.

A data grid is a specific type of grid where the resources are databases or data files. A data grid provides services that help users discover, transfer, and manipulate large datasets stored in distributed repositories and also, create and manage copies of these datasets. Data in a grid is syntactically, structurally and semantically heterogeneous but the grid provides an integrated view of data which abstracts out the underlying complexity behind a simple interface. The word 'grid' is an analogy with the electric power grid, which provides pervasive access to electric power (Foster and Kesselman 1999). Similarly, the idea behind a data grid is to provide pervasive access to data.

In a data grid, each participating node has full autonomy in terms of operations (the node conducts its own operations without being overridden by external operations), participation (the node can decide on the proportion of its resources to be shared in the grid), and access (the node can decide to whom access should be granted). Data grids are mostly read-only environments into which existing data is introduced or replicated. If the source of a data replica is updated, its corresponding replica on the grid is also modified 
(Venugopal, 2006). Currently data grids do not provide support for transactions, but the topic is on the agenda of the Open Grid Forum (OGF Transaction Management Research Group, 2005).

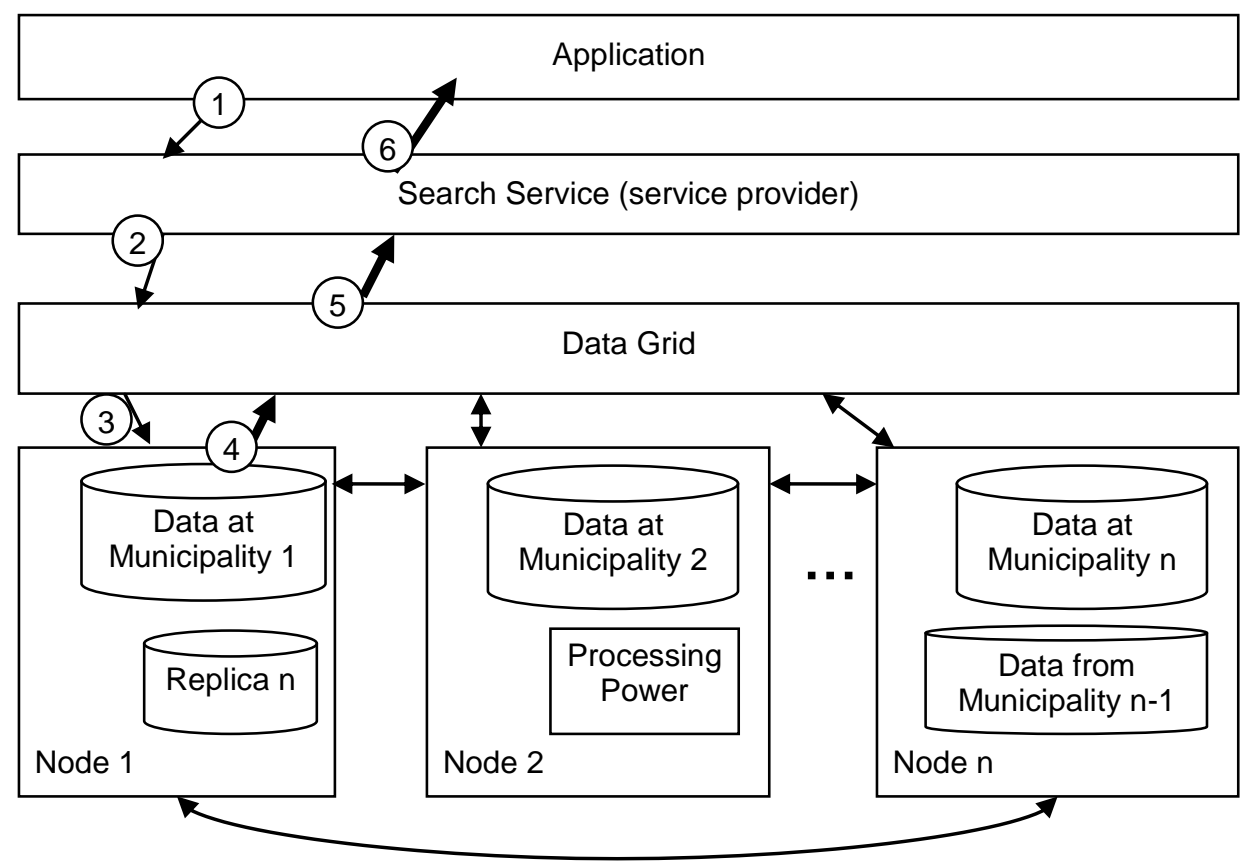

Figure 8. The data grid model

Data grids carry metadata about the collaborating datasets which is stored in a metadata catalogue and carries the logical dataset name together with the physical locations of the dataset and its replicas. The metadata can also include other attributes, such as those specified in 'ISO 19115 - Geographic Information-Metadata', to describe the data which can then be included in any data query.

The Open Grid Services Architecture - Data Access and Integration (OGSA-DAI) is a middleware product which supports the exposure of data resources, such as relational or XML databases, onto grids. Consistent interfaces to a number of popular database management systems are provided, and a collection of components for querying, transforming and delivering data via web services is also included. (OGSADAI website, 2008).

Figure 8 shows the sequence of events when performing a search for data in a data grid. The thick arrows indicate data flow.

1. The application calls the search service.

2. The search service queries the data grid.

3. The data grid locates the correct replica and does the necessary translations. It then passes the query to the node with a current replica of the data.

4. The resulting data is passed back to the data grid.

5. The data grid does the necessary backward translations and passes the resulting data back to the search service.

6. The resulting data is passed back to the application.

The Globus Toolkit, an open source software toolkit for building grid systems and applications, is developed by the Globus Alliance, an international collaboration that conducts research and development to create fundamental grid technologies. Its members include the Argonne National Laboratory at the University of Chicago, the National Center for Supercomputing Applications (NCSA) in the US, Univa 
Corporation, the University of Southern California Information Sciences Institute and the Royal Institute of Technology in Sweden.

On the commercial front Sybase Avaki Data Grid (refer to www.sybase.com) is a commercially available data grid solution where data remains with the authoritative sources, thereby eliminating inconsistencies and complexities introduced in managing multiple copies of the data required for compute grid applications. Avaki handles the performance and scalability needs in a clustered grid, an enterprisewide grid, or across a grid spanning multiple administrative domains.

Examples of data grids in the earth sciences that are based on georeferenced data are the Earth Systems Grid which integrates peta-bytes of data with analysis resources to provide an environment for next generation climate modelling and research; and NEESgrid which is used by earthquake researchers to aggregate information from sensor equipment, and used on a platform of high performance computing to design and execute experiments. The modelling and simulation of biological processes, coupled with the need for accessing existing databases, has led to the adoption of data grid solutions in the bio-informatics discipline. These projects involve federating existing databases and providing common data formats for the information exchange (Venugopal 2006).

\subsection{Comparative analysis}

Table 10. Comparative analysis of information federation models

\begin{tabular}{|c|c|c|c|}
\hline & Data harvesting & Federated database & Data grid \\
\hline Purpose & $\begin{array}{l}\text { Aggregate data from diverse } \\
\text { databases into a single centralized } \\
\text { database }\end{array}$ & $\begin{array}{l}\text { Provide an integrated view on } \\
\text { existing diverse databases with a } \\
\text { uniform and consistent interface }\end{array}$ & $\begin{array}{l}\text { Provide services to discover, } \\
\text { transfer, and manipulate large } \\
\text { datasets stored in distributed } \\
\text { databases and giving an } \\
\text { integrated view of the data }\end{array}$ \\
\hline $\begin{array}{l}\text { Unified view } \\
\text { provided by }\end{array}$ & $\begin{array}{l}\text { Single centralized database of } \\
\text { data }\end{array}$ & $\begin{array}{l}\text { Uniform and consistent interface } \\
\text { to the federated database }\end{array}$ & Standardized data grid services \\
\hline $\begin{array}{l}\text { Syntactic } \\
\text { translation and } \\
\text { semantic } \\
\text { interpretation }\end{array}$ & $\begin{array}{l}\text { Once off when harvested data is } \\
\text { loaded into the centralized } \\
\text { database }\end{array}$ & With each access & With each access \\
\hline Data updates & No, read-only & Equally read and write & Mostly read with rare writes \\
\hline $\begin{array}{l}\text { Transaction } \\
\text { support }\end{array}$ & $\mathrm{n} / \mathrm{a}$ & Yes & Not yet (being researched) \\
\hline Architecture & $\begin{array}{l}\text { Service-orientation for access to } \\
\text { the centralized database }\end{array}$ & $\begin{array}{l}\text { Service-orientation for unified } \\
\text { data access }\end{array}$ & $\begin{array}{l}\text { Service-orientation for unified } \\
\text { data access and underlying } \\
\text { architecture }\end{array}$ \\
\hline
\end{tabular}

\section{Evaluation}

In this section we describe the implementation issues for each model in the context of a national address database, and go on to analyse such an implementation based on the criteria set out in our evaluation framework for a national address database in South Africa. A comparative analysis is provided at the end of the section.

\subsection{Single centralized harvested national address database}

Figure 9 illustrates a national address database that is harvested from a number of data providers. We have added the four layers from our evaluation framework as a reference in the figure. Address data from the data providers is harvested at regular intervals and loaded into the single centralized database. 
An additional layer of abstraction on top of the central database provides standardized technologyindependent access to the database, and we call this layer the standardized NAD services. Once again, the OGC Web Feature Services are a suitable specification for services that query and retrieve address data from the central database. These standardized NAD services provide access to the centralized database in a uniform way with the fundamental services required such as traversing through the NAD in a specific suburb, finding a specific address record, etc. Application developers either access the central NAD through the standardized NAD services, or use the specialized services provided by independent service providers.

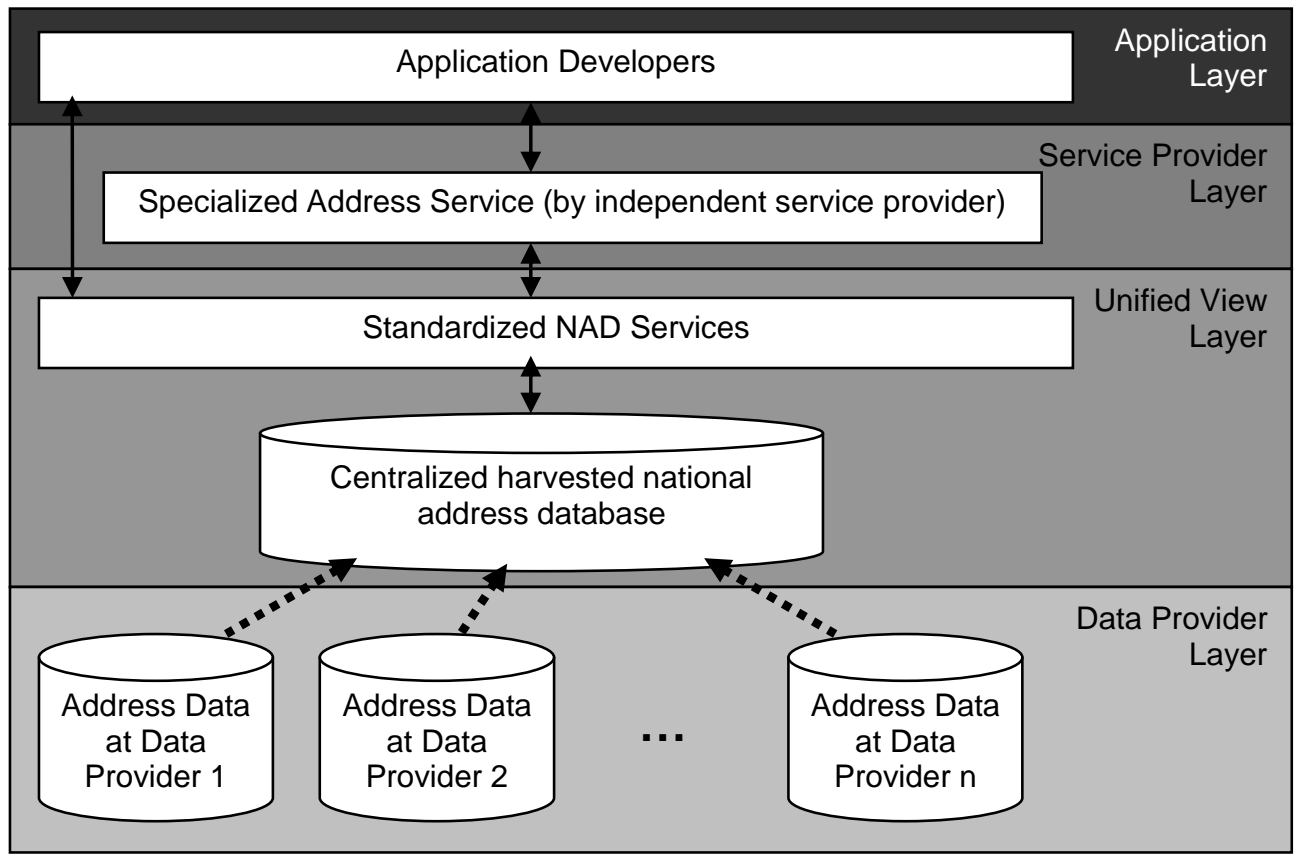

Figure 9. Single centralized harvested national address database

\subsubsection{Examples}

Australia. The Australian Geocoded National Address File (G-NAF®) is updated in an incremental format quarterly - usually in February, May, August and November. The Public Sector Mapping Agencies (PSMA) follow a semi-automated process of massaging contributor address data into a standardized format that is acceptable for merging into the G-NAF. Any address data that cannot automatically be converted into the standard address format, is subjected to a manual review process The data is distributed in a format known as a MapInfo file (GIS) in a single GIS data file. The PSMA is the custodian of the Geocoded National Address File (G-NAF). However, they are not the source of the data; PSMA acts as a clearinghouse by merging data from as many as 15 government agencies and organizations into the GNAF (Paull 2003).

Ireland. In Ireland a definitive reference directory for addresses is maintained by An Post and Ordnance Survey Ireland (OSi). The GeoDirectory, as it is called, combines postal addresses (where mail is delivered) and geographic addresses (a geo-code to position the address on a map) in one database which is available to organizations or individuals who require it. GeoDirectory updates are released four times a year by supplying customers with a single completely refreshed database (Fahey and Finch 2006).

\subsubsection{Evaluation}

Infrastructure. The standardized NAD services and/or the data exchange format of address data files accommodate heterogeneity in terms of operating system, DBMS and address data format. Other heterogeneity is eliminated when the data is loaded into the single centralized database. 
Data Providers. Different coverage areas of individual datasets are irrelevant in the data harvesting model, as all data is loaded into a single database. Duplicate addresses as provided by multiple data providers are either resolved when loading the data into the centralized database by applying a set of rules for picking the most pristine address to be loaded; alternatively duplicate addresses are loaded into the single database and the user specifies with parameters to each address data request which address data should be included in the query. Example parameters are a specific data provider, and minimum accuracy and quality requirements.

The data harvesting model accommodates the decentralized sources of address data by aggregating it into a single centralized database. However, a data provider gives up some of its autonomy by handing over the data to a centralized database. There is now a middle party - the administrator(s) of the centralized database.

Naming. A table of old and new names of places, as well as official and colloquial suburb names is stored in the single database. The table should include a spatial boundary for each name so that addresses such as the '29 Queens Way Hillcrest' problem described earlier can be resolved by searching surrounding suburbs. Any request for address data uses these tables to disambiguate a request for address data.

Address dynamics. In the data harvesting model the currency of the address data depends on how fast new and modified addresses can be loaded into the centralized database. From the Australian example it is clear that this process, even in a regulated environment, can be quite tedious involving manual reviewing of data.

In order to prevent duplication of efforts, data providers use the standardized NAD services to cross check whether an address already exists. Since all data is in one single database, summarized reports of address data per area can be published.

The feedback cycle from the general public involves three parties: the person in the general public who generates feedback to the provider, the data provider who modifies the address data if required, and the centralized database into which the modified address is loaded.

Accessibility. The standardized NAD services provide platform independent access to the address data to both application developers and service providers. Access anytime and from anywhere is addressed by providing online access to the single database via the standardized NAD services. The responsibility for up-time lies with the single entity in charge of the centralized database. For better performance, the single database can be replicated and load balancing techniques applied.

A potential problem in the model followed in the Australian and Irish examples above is that copies of the single centralized database are distributed to buyers of the data. Online access to the data is not the aggregator's responsibility, but that of whoever purchases the database and provides online access to it. This could result in a situation where service provider A makes services available on its copy of the database from the first quarter of a year, while service provider B's services are available on its copy of the database from the third quarter of a year. To an application developer who uses services from service providers $\mathrm{A}$ and $\mathrm{B}$ this results in conflicting views of the address data.

In the single database environment, billing for address data is handled by any of the current online transaction environments. Billing models include paying for accessing specific address data or paying a monthly subscription fee. Billing and accounting for use of the specialized services should be done by each independent service provider.

Security. In the case of the data harvesting model, security measures such as user authentication and granting access to data is implemented by the centralized database. Most database management systems, whether relational, spatial or object-oriented, have support for these security measures.

Organizational Issues. The data harvesting model requires a single organization to control and administrate the centralized national address database. If there is no organization with the mandate or the financial means to do this, the implementation of the data harvesting model is difficult, as it is preferable that some organization take responsibility for the coordination and loading of address data into the single centralized database. 


\subsection{A federated national address database}

In this model each data provider makes its database of address data available to the federation. A data provider's database has to be online in order to participate in the federated national address database, but it can be used for any other local operations while participating in the federation. Figure 10 illustrates the mapping between local and global representations in the architecture of a federated national address database.

The address data specific mappings, such as interpreting semantic differences, are implementation dependent and have to be developed specifically as part of the federated national address database. The unified view layer exposes a set of standardized NAD services, similarly to the harvested NAD.

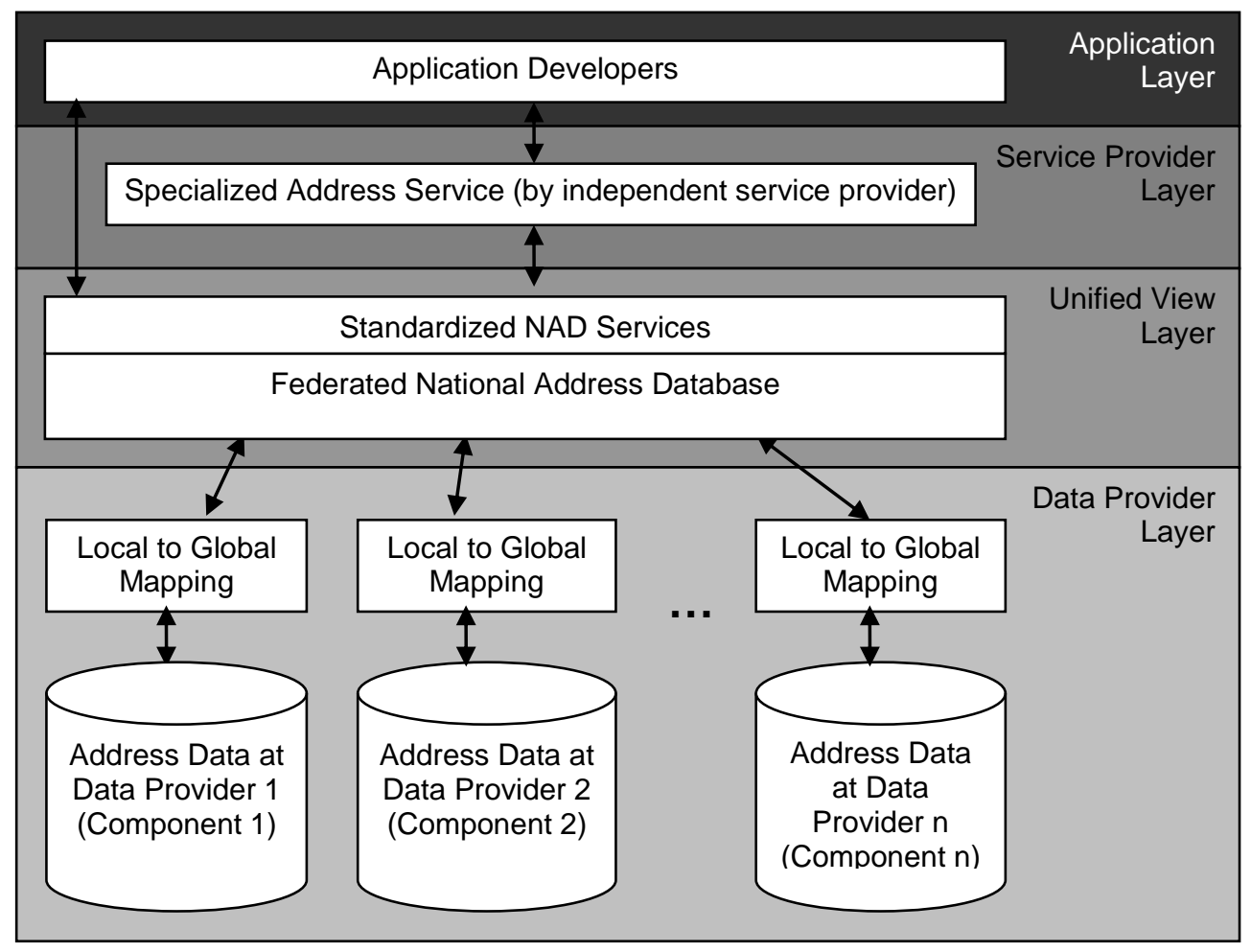

Figure 10. Federated national address database

\subsubsection{Examples}

Egypt. Although the example we present here is not a federated national address database, it is an example of a federated national database of land information, in many ways similar to address data. Tuladhar et al. (2005) propose a federated data model for the situation in Egypt where land ownership, state owned land data, cadastral data, topographic data and tax data are maintained by four different government departments. These datasets are maintained and stored at their respective departments at provincial level (i.e. sub-national level). The federated data model allows integrated access to the databases on a national level, while control over the maintenance of the data remains at the provincial government departments.

\subsubsection{Evaluation}

Infrastructure. In the federated database mapping from local to global data representation happens on the fly with each data request, thus the complexity of the local/global mapping influences the performance of address data queries.

Data Providers. The federated database by definition provides access to decentralized sources of data. Metadata such as the coverage area of a dataset and the data provider for the dataset are stored in separate tables (either at individual data providers or at a centralized location) and used whenever a distributed 
query is executed. Duplicate addresses from multiple data providers are either resolved by the distributed query mechanism, or passed back to the requester to resolve. For example, if the requester is an independent service provider, a statistical probability for the address with the largest probability of being correct can be added before passing the address back to the application layer.

Naming. The old and new names of places are stored for example, in a designated component database; the same applies to official and colloquial suburb names. The federated NAD cannot rely on underlying data providers to resolve all naming ambiguities; therefore the disambiguation functionality has to be implemented in the unified view layer.

Address dynamics. The currency of address data depends on the currency of the underlying component database. Since these databases reside with the data providers, there is no delay from updating to publishing address data. As soon as the data is updated in the component database, it is available in the federated NAD.

In order to prevent duplication of efforts, data providers can use the standardized NAD services to cross check whether an address already exists.

The feedback cycle from the general public involves two parties: the person in the general public who generates feedback to the provider, and the data provider who modifies the address data if required.

Accessibility. The standardized NAD services provide platform independent access to the address data, and can be used by both application developers and independent service providers. In the data harvesting model there is one entity - the centralized database - of which the uptime has to be managed; in the federated database each individual component database's uptime has to be ensured. If one of the components is off-line, the accessibility of the federated national address database is reduced, but the remaining parts of the federated database can still be accessed.

Billing for address data is handled by any of the current online transaction environments and has to be integrated into the federated database on the unified view layer. Billing and accounting for use of the specialized services should be done by each independent service provider.

Security. Security measures such as user authentication and granting access to data are implemented in the federated database as part of the unified layer. A user with access to an underlying component database does not have access to the federated database, but a separate user account on the federated database level is required.

Organizational Issues. Federated databases are typically created within a single organization. The participation of a component database is granted and controlled from a central point. If there is not a single organization with the mandate to establish and maintain a national address database a tightly coupled solution such as a federated database is difficult to implement.

\subsection{National address data grid}

In the national address data grid, each data provider makes its address data available on the grid, and can opt to make other resources such as storage space and processing power available as well. Since data grids are mostly read-only environments into which existing data is introduced or replicated, this fits the scenario of each local authority maintaining its own address database but making it available to the national address data grid whenever it is updated. Interoperability mechanisms to handle the heterogeneity in address format and semantics of the underlying data providers' databases has to be developed specifically for the national address data grid. 


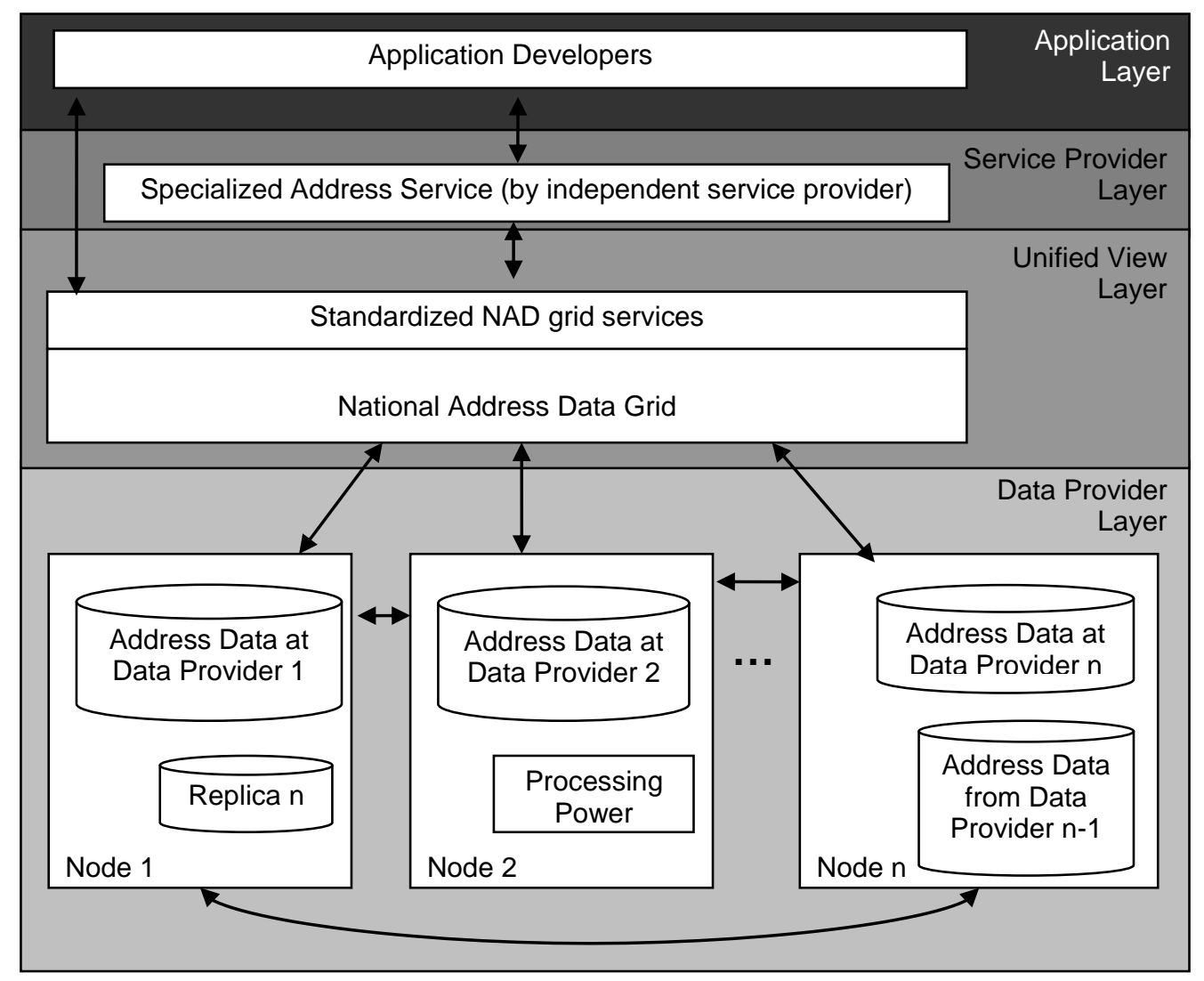

Figure 11. The national address database as a data grid

The standardized NAD grid services once again provide the uniform view to the underlying heterogeneous data sources. Venugopal et al. (2006) provide a taxonomy for data grids. According to this taxonomy, a national address data grid is organized as a federated model of stable data sources with interdomain scope where the virtual organization is created for collaboration and economic benefit of the individual participants and possibly regulated by a national authority at a later stage.

\subsubsection{Evaluation}

Infrastructure. In the data grid model the grid middleware addresses operating system heterogeneity, and OGSA-DAI is an example of grid middleware that takes care of difference in individual data providers' data representation. OGSA-DAI is compliant with the Globus Toolkit and also entirely implemented as web services, therefore providing a platform independent solution.

Data Providers. The metadata catalogue stores information about the decentralized sources of data including the coverage area of a dataset. Duplicate addresses from multiple data providers are either resolved by the distributed query mechanism, or passed back to the requester to resolve. Similarly to the FDBS, if the requester is an independent service provider a statistical probability for the address with the largest probability of being correct can be added before passing the address back to the application layer.

Naming. Old and new names, as well as official and colloquial names can be stored in anyone of the decentralized data sources in the grid. Similar to the federated database, the national address data grid cannot rely on underlying data providers to disambiguate all names, and thus the disambiguation functionality has to be implemented in the unified view layer as part of the grid middleware.

Address dynamics. In the data grid model the currency of address data depends on the currency of the underlying data providers' databases: as soon as the data provider has updated its address data, it is available to users of the NAD services. There is no time delay from update to availability.

Similar to the other two models, data providers can use the standardized NAD services to cross check whether an address already exists in order to prevent duplication of efforts. 
The feedback cycle from the general public involves two parties: the person in the general public who generates feedback to the provider, and the data provider who modifies the address data if required.

Accessibility. The standardized NAD services provide platform independent access to the address data, and can be used by both application developers and service providers. Access anytime and from anywhere is addressed by replicating the data provider databases in the grid; in the data grid, the uptime of several core nodes has to be ensured (and not the uptime of each individual node).

Data billing and accounting information can be handled by the grid middleware. There is somewhat more complexity involved in this model when not only data but also computing resources are shared.

Security. Security measures such as user authentication and granting access to data are taken care of by grid middleware. The virtual organization model is applied whereby for example, a user's access rights to data are derived from his/her membership in the virtual organization. This makes authentication more complex than in the other two models, but it has the advantage that user accounts do not have to be created by a central authority. Since the grid paradigm is still relatively new, not all security issues have been addressed by the grid community yet. However there is a lot of current research in this area.

Organizational Issues. A data grid provides the required flexibility of data providers entering and leaving the scene of contribution to the national address database. Thus the data grid could survive the transition from a national address database to which both officially regulated and unofficial address data providers contribute, to a national address register to which only officially regulated address data providers contribute. The data grid also does not rely on a single central organization to control and administrate the national address database, but allows a more organic type of existence with multiple contributors.

Harvey and Tulloch (2006) describe the 'federation-by-accord' data sharing model which involves a number of data producers who generally share their data with a number of other data users and producers in their network. The model is resilient to change and can afford to lose a major player without ruining the entire model. They found that this model approaches the ideal national SDI data-sharing environment in many ways, and that if it is integrated into the ongoing activities of local authorities, it becomes sustainable and the vehicle for enhancing data sharing. A data grid would support such a 'federation-byaccord' data sharing model.

\subsection{Comparative Analysis}

Table 11. Infrastructure

\begin{tabular}{llll}
\hline \multicolumn{1}{c}{ Criteria } & \multicolumn{1}{c}{ Data Harvesting } & \multicolumn{1}{c}{ Federated Database } & \multicolumn{1}{c}{ Data Grid } \\
\hline $\begin{array}{l}\text { Operating } \\
\text { System }\end{array}$ & $\begin{array}{l}\text { Once off when loading the data } \\
\text { into the single centralized database }\end{array}$ & $\begin{array}{l}\text { Dynamically with each data } \\
\text { request }\end{array}$ & $\begin{array}{l}\text { Dynamically with each data } \\
\text { request }\end{array}$ \\
\hline $\begin{array}{l}\text { DBMS } \\
\text { heterogeneity }\end{array}$ & $\begin{array}{l}\text { Once off when loading the data } \\
\text { into the single centralized database }\end{array}$ & $\begin{array}{l}\text { Dynamically with each data } \\
\text { request by middleware such as } \\
\text { ODBC or JDBC }\end{array}$ & $\begin{array}{l}\text { Dynamically with each data } \\
\text { request by the grid middleware, } \\
\text { e.g. OGSA-DAI }\end{array}$ \\
\hline $\begin{array}{l}\text { Address data } \\
\text { format }\end{array}$ & $\begin{array}{l}\text { Once off when loading the data } \\
\text { into the single centralized database }\end{array}$ & $\begin{array}{l}\text { Dynamically with each data } \\
\text { request }\end{array}$ & $\begin{array}{l}\text { Dynamically with each data } \\
\text { request }\end{array}$ \\
\hline
\end{tabular}

Table 12. Data Providers

\begin{tabular}{llll}
\hline \multicolumn{1}{c}{ Criteria } & \multicolumn{1}{c}{ Data Harvesting } & Federated Database & Data Grid \\
\hline Coverage area & $\begin{array}{l}\text { Irrelevant as all data is in one } \\
\text { database }\end{array}$ & Stored in separate metadata tables & Stored in the metadata catalogue \\
\hline $\begin{array}{l}\text { Decentralized } \\
\text { source of data }\end{array}$ & Not possible & Component databases & Grid nodes \\
\hline Multiple data & Either when loading the data or & Resolved on the fly or passed & Resolved on the fly or passed \\
\hline
\end{tabular}




\begin{tabular}{|c|c|c|c|}
\hline $\begin{array}{l}\text { providers per } \\
\text { area }\end{array}$ & $\begin{array}{l}\text { stored as an attribute of the } \\
\text { address }\end{array}$ & back to the requester to resolve & back to the requester to resolve \\
\hline
\end{tabular}

Table 13. Naming

\begin{tabular}{llll}
\hline \multicolumn{1}{c}{ Criteria } & \multicolumn{1}{c}{ Data Harvesting } & \multicolumn{1}{c}{ Federated Database } & \multicolumn{1}{c}{ Data Grid } \\
\hline $\begin{array}{l}\text { Suburb names } \\
\text { and name } \\
\text { changes }\end{array}$ & $\begin{array}{l}\text { Disambiguation information } \\
\text { stored in the centralized database }\end{array}$ & $\begin{array}{l}\text { Disambiguation information } \\
\text { stored in one of the component } \\
\text { databases }\end{array}$ & $\begin{array}{l}\text { Disambiguation information } \\
\text { stored at one of the grid nodes } \\
\text { pisambiguation functionality } \\
\text { provided by the centralized } \\
\text { database }\end{array}$ \\
\end{tabular}

Table 14. Address Dynamics

\begin{tabular}{llll}
\multicolumn{1}{c}{ Criteria } & Data Harvesting & Federated Database & Data Grid \\
\hline $\begin{array}{l}\text { New } \\
\text { developments }\end{array}$ & Time delay & Immediate & Immediate \\
\hline $\begin{array}{l}\text { Previously } \\
\text { unaddressed } \\
\text { areas }\end{array}$ & Time delay & Immediate & Immediate \\
\hline $\begin{array}{l}\text { Address cross } \\
\text { checking }\end{array}$ & Standardized NAD services & Standardized NAD services & Standardized NAD services \\
\hline Feedback & Three parties & Two parties & Two parties \\
\hline
\end{tabular}

Table 15. Accessibility

\begin{tabular}{|c|c|c|c|}
\hline Criteria & Data Harvesting & Federated Database & Data Grid \\
\hline $\begin{array}{l}\text { Providing } \\
\text { services }\end{array}$ & $\begin{array}{l}\text { Platform independent web } \\
\text { services such as OGC web } \\
\text { feature services }\end{array}$ & $\begin{array}{l}\text { Platform independent web } \\
\text { services such as OGC web } \\
\text { feature services }\end{array}$ & $\begin{array}{l}\text { Platform independent web } \\
\text { services such as OGC web } \\
\text { feature services }\end{array}$ \\
\hline $\begin{array}{l}\text { Billing and } \\
\text { accounting }\end{array}$ & Online transaction environment & Online transaction environment & Still being researched \\
\hline Using services & $\begin{array}{l}\text { Platform independent web } \\
\text { services such as OGC web } \\
\text { feature services }\end{array}$ & $\begin{array}{l}\text { Platform independent web } \\
\text { services such as OGC web } \\
\text { feature services }\end{array}$ & $\begin{array}{l}\text { Platform independent web } \\
\text { services such as OGC web } \\
\text { feature services }\end{array}$ \\
\hline Access anytime & Single server & $\begin{array}{l}\text { Each server with a component } \\
\text { database }\end{array}$ & A number of core nodes \\
\hline $\begin{array}{l}\text { Access from } \\
\text { anywhere }\end{array}$ & Internet & Internet & Internet \\
\hline $\begin{array}{l}\text { Ease of } \\
\text { publishing }\end{array}$ & $\begin{array}{l}\text { Data providers have to convert } \\
\text { their data into the address data } \\
\text { exchange format }\end{array}$ & $\begin{array}{l}\text { Data providers store data in their } \\
\text { choice of database }\end{array}$ & $\begin{array}{l}\text { Data providers store data in their } \\
\text { choice of database }\end{array}$ \\
\hline
\end{tabular}

Table 16. Security

\begin{tabular}{lccc}
\hline Criteria & Data Harvesting & Federated Database & Data Grid \\
\hline User & User accounts in the centralized & User accounts of the federated & Authentication is established \\
\hline
\end{tabular}




\begin{tabular}{llll}
\hline $\begin{array}{l}\text { authentication, } \\
\text { access and } \\
\text { privacy }\end{array}$ & database & database & through the virtual organization \\
& possible & Data updates and transactions are & Data updates are theoretically \\
& allowed in the federated database, & possible, but transactions not yet \\
but should be controlled by the & available \\
local data provider for proper & \\
dataset management
\end{tabular}

Table 17. Organizational Issues

\begin{tabular}{llll}
\hline Criteria & Data Harvesting & Federated Database & Data Grid \\
\hline $\begin{array}{l}\text { Official } \\
\text { custodians and } \\
\text { unofficial data } \\
\text { providers }\end{array}$ & $\begin{array}{l}\text { Requires central coordination and } \\
\text { organization }\end{array}$ & $\begin{array}{l}\text { Requires central coordination and } \\
\text { organization }\end{array}$ & $\begin{array}{l}\text { Provides flexibility for data } \\
\text { providers to come and go }\end{array}$ \\
\hline
\end{tabular}

\section{Conclusion}

We have presented the status of spatial address data within the context of SDI and thereby illustrating that the sources for address data are distributed and not under centralized coordinated control. We illustrated the need for address data in both the public and private sector, and justified the need for address-related services on a national level, making specific reference to South Africa. Thus, there is a demand for non-trivial address-related services. We have further shown that there are typically numerous and diverse sources of address data, resulting in ambiguities and heterogeneities in the address data. Therefore, one has to work with standard, open interfaces for address data content as well as access to the address data.

Our novel evaluation framework describes important criteria for a national address database and we use the South African scenario to contextualize the framework. We used this framework to evaluate three information federation models: data harvesting, federated databases and data grids, and compare implementation issues for a national address database in the form of each of the models. The large number of organizations involved in a national address database, as well as the lack of a single organization tasked with the management of a national address database, presents the data grid as an attractive alternative to the other two models. The data grid provides for a more loosely coupled architecture, thereby allowing for more diversity and heterogeneity.

The typology for local government sharing in the United States, as presented by Harvey and Tulloch (2006), describes some disadvantages to giving a single organization the authority over data production and sharing. Both the data harvesting model and the federated database model require a single organization to take control. Harvey and Tulloch report that a federation-by-accord, although difficult to establish, once integrated into ongoing activities, can become sustainable and a suitable vehicle for enhancing data sharing. Our novel approach to a national address database as a data grid corresponds to the 'federation-by-accord' data sharing model which can afford to lose a major player without ruining the entire model.

As part of our THRIP project which is funded by the Department of Trade and Industry (dti) and our industry partner, AfriGIS, we are setting up a data grid with the Globus toolkit at the University of Pretoria, and are busy expanding it to AfriGIS and our collaborators on the project in Dhaka, Bangladesh. Some very basic address verification services are currently running on the grid at the university, and the plans are to expand on these. As part of our research we are currently investigating charging frameworks for a national address database on the grid. Our data grid benefits from the service-oriented architecture of the Globus Toolkit, which provides for a loosely coupled solution. We believe that there are also large benefits to be gained from the more traditional grid services in Globus such as those for resource scheduling (GRAM) and large file transfers (GridFTP), and this provides for interesting research questions for future phases of our research. 
Data grids are a more recent development and current implementations are still mostly in the scientific research environment. At this stage most data grid implementations focus on high volumes of data and high processing loads whereas an implementation of a national address data grid would focus on pervasive access to address-related resources (data and services), as envisaged with the original analogy to the electrical power grid.

\section{Acknowledgements}

This work is supported in part by the South African Department of Trade and Industry (dti) and AfriGIS (Pty) Ltd.

\section{References}

Arefin, M.A., SAdiK, M.S., CoetzeE, S.M., Bishop, J.M., 2006. Alchemi vs Globus: a performance comparison. 4th International Conference on Electrical and Computer Engineering, December 1921 2006, Dhaka, Bangladesh.

BAKer, M., Apon, A., Ferner, C., Brown, J., 2005. Emerging grid standards. IEEE Computer April 2005, 38(4), 43-50.

BRITISH STANDARDS INSTITUTION, 2006. BS 7666:2006. Spatial datasets for geographical referencing.

Clodoveu, A.D. JR AND FonseCA, F.T., 2007. Assessing the certainty of locations produced by an address geocoding system. Geoinformatica, 11, 103-129.

CoetzeE, S.M. AND Bishop, J.M., 1998. A new way to query GIS on the web. IEEE Software, May/June 1998, 15(3), 31-40.

CoetzeE, S.M. AND CoOPER, A.K., 2007. What is an address? South African Journal of Science, Nov/Dec 2007, 103(11/12), 449-458.

Coetzee, S.M., Cooper, A.K., Lind, M., McCart Wells, M., Yurman, S., Wells, E., Griffiths, N. AND NiCHOLSON, M.J., 2008. Towards an international address standard. $10^{\text {th }}$ Global Spatial Data Infrastructure Conference (GSDI-10), 25-29 February 2008, St Augustine, Trinidad.

CONSTitution of the RePublic OF SOUth AFricA, 1996. Available from: http://www.polity.org.za/polity/govdocs/constitution/index.html [Accessed 19 March 2008].

Crompvoets, J., Bregt, A., Rajabifard, A., Williamson, I., 2005. Assessing the worldwide developments of national spatial data clearinghouses. International Journal of Geographical Information Science, October-November 2004, 18(7), 665-689.

FAHEY, D. AND Finch, F., 2006. GeoDirectory Technical Guide [online]. An Post GeoDirectory Limited. Available from: http://www.geodirectory.ie/Downloads.aspx, [Accessed 19 March 2008].

FinANCIAl InTELligence CENTRE ACT OF SOUTH AFRICA, 2001. Available from: http://www.acts.co.za/fica/index.htm [Accessed 19 March 2008].

Foster, I. AND Kesselman, C., 1999. Preface in The GRID Blueprint for a New Computing Infrastructure, Morgan Kaufmann Publishers, San Francisco USA.

FOSTER, I., 2002. What is the Grid? A three point checklist, GRIDToday, 22 July 2002, 1(6).

HARVEY, F. and TUlLOCH, D., 2006. Local-government data sharing: Evaluating the foundations of spatial data infrastructures. International Journal of Geographical Information Science, August 2006, 20(7), 743-768.

GEODIRECTORY WEBSITE [online]. An Post GeoDirectory Limited. Available from: http://www.geodirectory.ie [Accessed 19 March 2008].

GeORgIAdoU, S.K., PURI, S.K. and SAHAY, S., 2006. Towards a potential research agenda to guide the implementation of spatial data infrastructures - A case study from India. International Journal of Geographical Information Science, November 2005, 19(10), 1113-1130. 
INTERNATIONAL ORGANIZATION FOR STANDARDIZATION (ISO), 2003. ISO 19112:2003. Geographic information - Spatial referencing by geographic identifiers, International Organization for Standardization (ISO), Geneva, Switzerland.

Jacoby, S., Smith, J., Ting, L., AND Williamson, I., 2002. Developing a common spatial data infrastructure between state and local government — an Australian case study. International Journal of Geographical Information Science, June 2002, 6(4), 305-322.

MASSER, I., RAJABIFARD, A. AND WILLIAMSON, I., 2007. Spatially enabling governments through SDI implementation. International Journal of Geographical Information Science, July 2007, 22(1), 520.

MATHERI, M., 2005. Challenges facing the creation of a standard South African address system. FIG Working Week and ${ }^{\text {th }}$ Global Spatial Data Infrastructure Conference (GSDI-8), 16-21 April 2005, Cairo, Egypt.

McDougall, K., Rajabifard, A. AND Williamson, I., 2005. What will motivate local governments to share spatial information? SSC 2005 Spatial Intelligence, Innovation and Praxis: The national biennial Conference of the Spatial Sciences Institute, September 2005, Melbourne, Australia.

MORAD, M., 2002. British standard 7666 as a framework for geocoding land and property information the UK. Computers, Environment and Urban Systems, September 2002, 26(5), 483-492.

OGF Transaction Management Research Group (GGF), 2005. Proposed Grid Transactions RGCharter [online]. Open Grid Forum. Available from: http://www.ogf.org/tm-rg-charter.html [Accessed September 2006].

OGSA-DAI WEBSITE [online]. University of Edinburgh. Available from: http://www.ogsadai.org.uk/ [Accessed 19 March 2008].

PAull, D., 2003. A Geocoded National Address File for Australia: The G-NAF What, Why, Who and When [online]. PSMA Australia Limited. Available from: http://www.psma.com.au/resources/theg-naf-what-why-who-and-when [Accessed 19 March 2008].

Public Sector Mapping Agencies (PSMA) Australia Website [online]. Available from: www.psma.com.au [Accessed 19 March 2008].

Rajabifard, A., Binns, A., MASSER, I. and Williamson, I., 2006. The role of sub-national government and the private sector in future spatial data infrastructures. International Journal of Geographical Information Science, August 2006, 20(7), 727-741.

Rase, D., BJörnsson, A., Probert, M., HAuPt, M., (Ed.)., 2002. INSPIRE Reference Data and Metadata Position Paper [online]. INSPIRE Reference Data and Metadata working group. Available from: http://www.ec-gis.org/inspire/reports/position papers/inspire rdm pp v4 3 en.pdf, [Accessed 19 March 2008].

SHETH, A.P. AND LARSON, J.A., 1990. Federated database systems for managing distributed, heterogeneous, and autonomous databases. ACM Computing Surveys, September 1990, 22(3), 183236.

SOUTH AFriCAN BUREAU OF STANDARDS (SABS), 2008. SANS 1883: Draft Standard. Geographic Information - Address Standard. SABS Technical Sub-committee 71E - Geographic Information, SABS, Pretoria, South Africa.

Spatial Data InFrastructure ACT OF SOUTH AFriCA, 2003. Available from: http://llnw.creamermedia.co.za/articles/attachments/01109_spatdatinfraa54.pdf [Accessed 19 March 2008].

Treadwell, J., (Ed.), 2006. OGSA Glossary of Terms [online]. Open Grid Forum (OGF). Available from: http://www.ggf.org/Public_Comment_Docs/Documents/Apr-2006/draft-ggf-ogsa-glossary-1.5006.pdf [Accessed 19 March 2008].

Tuladhar, A., Radwan, M., Kader, F. AND El-Ruby, S., 2005. Federated data model to improve accessibility of distributed cadastral databases in land administration. $8^{\text {th }}$ Global Spatial Data Infrastructure Conference (GSDI-8), 16-21 April 2005, Cairo, Egypt. 
Venugopal, S., Buyya,.R. AND Ramamohanarao, K., 2006. A taxonomy of data grids for distributed data sharing, management and processing. ACM Computing Surveys, March 2006, 38(3), 1-53.

WiLliamson, I., GRANT, D. AND RAJABIFARD, A., 2005. Land administration and spatial data infrastructures. $8^{\text {th }}$ Global Spatial Data Infrastructure Conference (GSDI-8), 16-21 April 2005, Cairo, Egypt.

YILDIRIM, V. AND YomRaLIOGLU, T., 2004. An address-based geospatial application. FIG Working Week, 22-27 May 2004, Athens, Greece. 